Association for Information Systems

AIS Electronic Library (AISeL)

ICEB 2012 Proceedings

International Conference on Electronic Business

(ICEB)

Fall 10-12-2012

\title{
The Moderating Effect of Legitimacy and Reputation on SMEs in a B2B Environment
}

Kai Li

Timon C. Du

Zhangxi Lin

Follow this and additional works at: https://aisel.aisnet.org/iceb2012

This material is brought to you by the International Conference on Electronic Business (ICEB) at AIS Electronic Library (AISeL). It has been accepted for inclusion in ICEB 2012 Proceedings by an authorized administrator of AIS Electronic Library (AISeL). For more information, please contact elibrary@aisnet.org. 


\title{
The Moderating Effect of Legitimacy and Reputation on SMEs in a B2B Environment
}

\author{
Kai Li ${ }^{1}$, Timon C. $\mathrm{Du}^{2}$, Zhangxi Lin $^{3}$ \\ 1. Dept. of Industrial Engineering, Nankai University, Tianjin, China \\ 2. The Chinese University of Hong Kong, Shatin, Hong Kong, China \\ 3. Texas Tech University, Lubbock, USA \\ likai@nankai.edu.cn, timon@baf.msmail.cuhk.edu.hk, Zhangxi.lin@ttu.edu
}

\begin{abstract}
How to survive and grow has always been a serious problem faced by the small and medium sized enterprises (SMEs) on a B2B platform. A lot of researches in entrepreneurship field have proved the positive effects of entrepreneurial orientation on firms' performance, but few researchers studied how entrepreneurial orientation influences performance. Based on the institutional theory, this paper introduces legitimacy and reputation to try to explain how competitive aggressiveness affects SMEs' performance in a $\mathrm{B} 2 \mathrm{~B}$ environment. Based on the analysis of data from 400 SMEs on a B2B platform, several interesting findings are concluded. Competitive aggressiveness has a very significant positive influence on SMEs' performance. It is more important to firms on a B2B platform than traditional firms. Both legitimacy and reputation plays a moderator role in this process; the better corporate legitimacy and reputation are, the stronger this influence is.
\end{abstract}

Keywords: competitive aggressiveness; reputation; legitimacy; performance

\section{Introductions}

Since e-commerce arose in the 1990s, it has been accepted and promoted by more and more traditional companies because of its convenience and low cost. With the rapid development of Internet, e-commerce platform develops quickly, and the B2B model has

Proceedings of the Twelfth International Conference on Electronic Business, Xi'an, China, October 12-16, 2012, 134-146. been widely accepted and applied. Therefore, a large number of new SMEs on B2B platforms appear [1]. A $\mathrm{B} 2 \mathrm{~B}$ environment is quite different from traditional business, and the different game rules lead to serious obstacles to the growth of SMEs. So, a majority of new ventures created in the B2B environment grow slowly and have a short life cycle. There are some other new ventures developing quickly. They make full use of the Internet and apply the concept of e-commerce to business operations successfully. As a consequence, their business efficiency improved, and their competitiveness was enhanced. In a word, the emergence of e-commerce has deeply affected the SMEs' growth, and it is important for SMEs to study how to survive and grow on B2B platforms.

At present, there have been a lot of researches about traditional enterprises' growth. Some mature theories were proposed about entrepreneurial orientation, legitimacy and performance. Lumpkin and Dess pointed that entrepreneurial orientation consisted of five parts: autonomy, innovativeness, risk-taking, proactiveness, and competitive aggressiveness. Some scholars proved that proactiveness was closely related to a company's growth. High proactiveness helps the company to obtain first-mover advantage. Thus, it can obtain a better performance. While the institutional theory suggests that companies with high proactiveness are likely to face legality obstacles.

Actually, the traditional theory may not apply to SMEs on B2B platforms, because SMEs on B2B 
platforms are special. Firstly, the enterprises on B2B platforms are very easy to set up, resulting in greater competition, so the impact of competitive aggressiveness is more obvious. The relationship between competitive aggressiveness and performance is rarely involved in the existing researches. Secondly, on B2B platforms, buyers can obtain less information about the products and sellers than traditional face-to-face trade, so that they urgently require more specific information of the transaction environment. This means the impact of legitimacy on performance has become pivotal. Thirdly, the particularity of e-commerce makes an enterprise's reputation become closely re- lated to the success of the transaction, because reputation is a prerequisite for the transaction. As has been pointed, reputation can guarantee the success of the transaction in a space-time point without face-to-face. On the contrary, if the buyers and sellers do not trust each other, no transactions can be achieved except real-time transactions in a space-time point [2].

Given the particularity of the SMEs on B2B platforms, this article is going to study the growth of these SMEs from the following four aspects: competitive aggressiveness, legitimacy, reputation and enterprise performance. The research model is proposed as Figure 1.

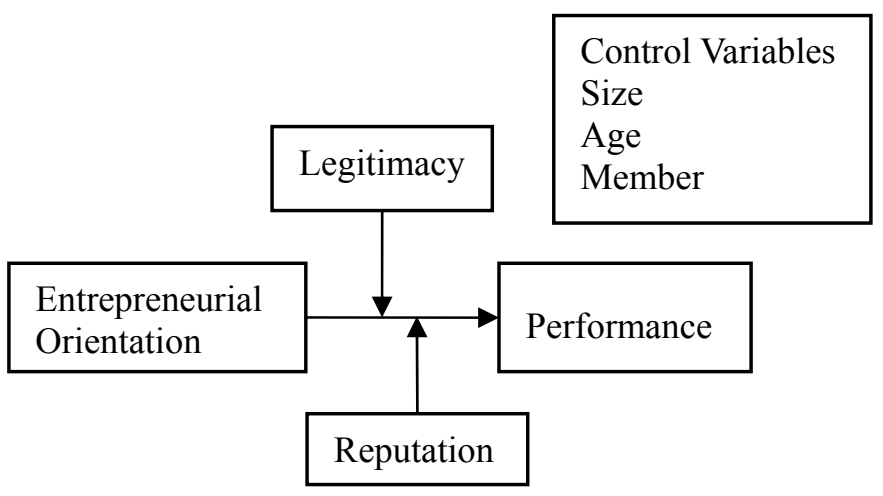

Figure 1. Research Model

\section{Literature Review}

\subsection{Entrepreneurial Orientation and Competitive} Aggressiveness

In the 1970s, scholars in strategy management field started to study on the entrepreneurial orientation [3]. Miller (1983) argued that entrepreneurship could be explained as the process by which organizations renew themselves and their markets by pioneering, innovation, and risk taking [4]. Lumpkin and Dess (1996) hold the idea that the essence of entrepreneurship is new entry, which can be accomplished by entering new or established markets with new or existing goods or services [5]. Then they pointed out that the entrepreneurial orientation refers to the processes, practices, and decision-making activities that lead to new entry.
Knight (1997) thought the entrepreneurship or entrepreneurial orientation is a characteristic attitude and a series of behavior and process of organizations [6].

What's more, the entrepreneurial orientation can also be regarded as an enterprise-level strategic decision-making process through which enterprises achieve organizational goals and create competitive advantage. And this view has been generally recognized by the academia [7].

Above all, we think the entrepreneurial orientation is a kind of strategy making process on the internet platform where e-business companies run their business. During this process, the e-business enterprises achieve their goals and create competitive advantage. In addition, the intention and behavior of 
key persons who create the business are of great importance to this process.

In order to get precise measurements of entrepreneurial orientation, its dimension must be defined reasonably, while there is some debate about it. Mintzberg (1973) suggested adaptive, entrepreneurial, and planning modes of strategy making [8]. Miller (1983) suggested innovativeness, risk-taking and proactiveness, which is widely accepted. Among the dimensions, innovativeness means companies encourage new ideas and practice that are likely to create new products, service or techniques. And risk-taking means that companies are interested in assuming liability, promising large scale of resource and obtaining high return by seizing opportunity in market. Proactiveness means rapid innovation and quick introduction of a product or service to the market.

Lumpkin and Dess (1996) developed the three dimensions of entrepreneurial orientation to five: autonomy, innovativeness, risk-taking, proactiveness and competitive aggressiveness. Autonomy means individuals or groups come up with new ideas or vision and try to put them into effect autonomously. Competitive aggressiveness means that companies challenge competitors directly and frequently on the purpose of entering a certain market or improving present position.

Entrepreneurial enterprises usually pay much attention to opportunities and threats in the external environment, which is closely related to the existence and development of a company. In some early research, scholars put forward some behavior about the diversity of competitive aggressiveness and how companies react to those opportunities and threats during their entrepreneurial process. MacMillan (1983) discussed how the preemptive strategies and competitive initiative work when a company occupies an advantageous position [9]; Kotler and Singh (1981) described the Marketing warfare tactics [10]. Lieberman and Montgomery (1988) developed some typical methods used for companies to attain competitive advantage, such as being "first mover" [11]. However, these scholars left out the competitive aggressiveness as one dimension of entrepreneurial orientation.

Miller (1983) pointed out that entrepreneurial enterprises pay much attention to the innovation of product market, taking risk, and putting forward foresighted innovation to beat competitors. According to this theory, competitive aggressiveness was put forward. Then Lumpkin and Dess (1996) applied this dimension to measure the reaction of a company in front of threats, and regarded competitive aggressiveness as a supplement of elements of entrepreneurial orientation.

Chen Linfen (2007) defined competitive aggressiveness as a degree that a company exceeds its competitor, that is, an aggressive attitude to the behavior of its competitors [12]. Covin and Slevin considered that proactiveness and competitive aggressiveness are equal. Knight (1997) stated that the proactiveness is to be more aggressive to face competitors, so the proactiveness here is similar to the competitive aggressiveness. However, Lumpkin and Dess (2001) pointed out in Linking two dimensions of entrepreneurial orientation to firm performance that the differences between proactiveness and competitive aggressiveness cannot be left out and they are independent and not covariant based on the data of 94 companies in 13 industries, therefore they cannot become one [13]. Consequently, Yang Yuli pointed out in Research on entrepreneurial orientation of New Enterprise that the proactiveness describes the active reaction of companies to opportunities, while the competitive aggressiveness stresses on the passive action to threats [14]. The former is how to strive for future market with potential competitors, and the latter is 
how to strive for the present market.

In conclusion, we define the competitive aggressiveness as a degree measuring the attitude to opportunities and threats, in other words the reaction to the competition from present competitors. While on the platform of the internet, performance and criterion of competitive aggressiveness enormously change. Marketing and purchasing of traditional companies rely on people (salesman and buyer for example), and source of cost is diverse. However, in terms of internet, information is more transparent and cost is more or less the same among different enterprises. Successful trade depends on operations on the platform of internet. The competition transfers from reality into virtual world, the internet. The information, at the same time the background and metrics of the relationship of competitive aggressiveness and performance has changed. So for the development of a new company, it is meaningful to explore whether we can improve performance by enhancing the competitive aggressiveness.

\subsection{Legitimacy}

Legitimacy is a core concept of the institutionalism. Max Webber is one of the scholars first to propose the concept of legitimacy. When discussing the bureaucratic administrative activities, Weber proposed the concept of organizational legitimacy, namely, organizational activities staying consistent with the mandatory rules and the structure. After Weber, many scholars did in-depth researches about legitimacy from organizational and management perspectives. After that, the so-called new institutionalism in the organization and management studies gradually formed [15].

New institutionalism develops the concept of legitimacy, extending it to the general organizational systems from the power system and highlighting the social cognition system. It argues that because of the limited rationality and the law of environmental uncertainty in decision-making, it is difficult to directly determine the value and acceptability of the organization, so people often judge the organizational legitimacy according to the consistency of organization and system.

The existing system constrains the behavior of new enterprises, making the system itself become the legitimacy constraints for new enterprises. About legitimacy constraints, scholars have different divisions.

Aldrich \& Fiol (1994) took the lead in dividing legitimacy into social and political legitimacy and cognitive legitimacy. The social and political legitimacy includes the recognition from key stakeholders and government officials that enterprises' behaviors and forms are consistent with laws, rules and norms; the cognitive legitimacy includes the extent to which the enterprises has been accepted by public, which is determined primarily by the external world's understanding about the enterprise's knowledge[16].

Suchman (1995) proposed three kinds of legitimacy: pragmatic legitimacy, moral legitimacy and cognitive legitimacy. Pragmatic legitimacy comes from the self-interested consideration of stakeholders, which is the reason for their support to the organization's policies. Accordingly, the enterprises should show their credibility and concern with the interests of stakeholders. Moral legitimacy arises from that the enterprises should do right things. Cognitive legitimacy constraints derive from the community's assumption about what the organization should be.

At present, the division of Scott is widely recognized, which divided the legitimacy constraints into regulative legitimacy, normative legitimacy and cognitive legitimacy. First, the regulative legitimacy includes not only government regulation, but also rules and standards created by a variety of credit associations, professional groups and leading organizations. 
For example, new enterprises can obtain consumers' recognition by getting quality certification. Second, the normative legitimacy constraints root in social norms and values or a level of social environment of new enterprises. For instance, new enterprises on the internet can win the trust of customers by joining the security system on B2B platforms. At last, the cognitive legitimacy constraints result from the widely held public beliefs and assumptions taken for granted, and the belief system disseminated by knowledge group, etc [17].

At a certain stage, system/social structure, norms, values, beliefs and the framework of definition are stable. So, people will make the general perception or assumption about the appropriateness, fitness and desirability of organizational activities according to the institutions, namely, the level of the legitimacy [18].Organizations should concern about the institutional viewpoints of resource holders who are critical to the organizations' reputation and viability, and take the initiative to get legalized instead of being passively obedient to obtain legitimacy [19]. Legitimacy is useful for new enterprises to get access to resources for growth. Furthermore, legitimacy itself is a key resource for a new enterprise's growth and is beneficial for enterprises to obtain other required resources [20].

In summary, new enterprises should take legalizing actions to get a clear idea of the social definition of corporate identity and meet the legitimacy requirements of the stakeholders. New SMEs on the B2B platform may face a higher legitimacy threshold than traditional enterprises in the traditional context. The latter can show their strength by displaying business entity in order to obtain the recognition of stakeholders. But in the B2B environment, since enterprises' stakeholders can not directly investigate the enterprise and its products, their acceptance of enterprise largely depends on the information about the enterprise provided on the internet. Compared with SMEs' self-descriptions, people are more likely to believe the B2B platform's description and evaluation of the enterprises. Therefore, the norms on e-commerce platform provide a channel for SMEs to get the trust of stakeholders. Concretely speaking, the SMEs do what norms ask, and then the platform provides some recognition to the enterprise so that it enables the enterprises to gain normal legitimacy. When the norms on e-commerce platform are widely recognized, SMEs should actively comply with the rules to get legitimacy recognition and support from stakeholders.

\subsection{Reputation}

Reputation is a comprehensive judgment and assessment of various economic organizations' credibility and ability to fulfill their commitment. Fombrun (1996) described corporate reputation as an overall reflection of its past behavior and results, which shows its ability to create value for stakeholders [21]. Caves and Porter (1977) proposed that excellent corporate reputation is not only an intangible asset, but also a strategic competitive advantage to improve long-term profitability [22].

Williamson in modern institutional economics presented that people are born with opportunism. Since the individual doesn't have exact knowledge of when and where opportunism will take place, he has to take protective measures to keep its hazards away. Opportunism has made transaction process consume more resources. However, reputation makes it easy for all participations to get access to resources with low cost and acquire the surplus without any resource allocated in the contract and execution, which cannot get through contract originally due to the presence of information costs.

During an online transaction, it's difficult for buyers and sellers to meet each other, so buyers will 
have no choice but to rely on the description about goods given by the other side, which further increases the information asymmetry and highlights the role of reputation. Zhang Weiying (2001) considered reputation as a lower-cost mechanism instead of law to guarantee transactions in some cases, especially in the field beyond the law [23]. Taking Taobao.com as an example, Li Weian and Wu Desheng (2007) emphasized the role of personal and collective reputation in the governance of transactions when the legal system and social credit system are absent, indicting private order can be an alternative of public order [24]. Based on the online transaction data, Yang Juzheng, Zhang Weiying and Zhou Li' an (2008) suggested reputation can substitute surveillance to a certain extent [25]. They hold that large enough future benefits are needed as an incentive to maintain the cooperation when short-term breach of contract cannot be timely punished for the absence of favorable surveillance, hence reputation will become more necessary.

In conclusion, reputation is actually a complementation and alternative of formal institutions. It can reduce buyers' expectation about sellers' opportunism and transaction cost brought about by the information asymmetry.

\section{Hypotheses}

\subsection{Competitive aggressiveness and performance}

Competitive aggressiveness is closely related to enterprises' performance. On one hand, competitive aggressiveness is a response to threats. Companies focus on the interaction of both competitors and the market, manifested as participating in the competition decisively and effectively. Therefore, they tend to directly response to competitors in the form of a face-to-face way, in attempting to destroy the competitors. On the other hand, competitive aggressiveness can be regarded as the tendency of taking non-traditional competitive means to consolidate the market status. Ventures often take non-traditional tactics to challenge the market leader, analyze the target opponent's weaknesses and develop high value-added products. In addition, the findings of Jeffrey G. Covin and Teresa Joyce Covin (1990) showed that in a hostile and competitive environment, companies with high performance often show a positively aggressive orientation, while the poor performers tend to be more passive.

In fact, the theory above also works when it comes to companies on B2B platforms. Generally, companies with high competitive aggressiveness are often able to give competitors a serious blow, because it is vital for new entrants to compete with a positive attitude and a strong competitive behavior [26]. To gain a certain market share, they will take proactive means to compete with their competitors in all aspects. Otherwise, the new ventures can fail easily. Companies with strong competitive aggressiveness don't take conservative and enduring strategies, but to make use of their strengths to launch an active offensive to their opponents, so that they can capture the market share. In order to achieve this purpose, the enterprises have to pay close attention to market changes, and quickly solve problems about the operation and management of enterprises. With the problems solved, they will have good performance. According to the discussion above, this study hypothesizes:

H1: The competitive aggressiveness is positively related to the performance of SMEs in a B2B environment.

\subsection{Moderating effect of legitimacy}

Studies based on institutional and organizational relations find the legitimacy constraints rather than internal coordination and management factors is the main reason for liability of newness and a high mortality rate of new enterprises. Aldrich \& Fiol (1994) 
pointed out that many enterprises failed not because of the lack of market potential, but for the legitimacy issues such as failure to establish a relationship of trust with stakeholders, deal with competitive industry successfully and acquire institutional support, etc. The essence of growth of new enterprise is the process to embed system through choosing legitimizing strategy, overcoming the legitimacy threshold, and attaining resources.

As new entrants with high proactiveness in the market, new enterprises on the internet face higher legitimacy barriers than existing competitors in their field. High competitive aggressiveness reflects the strong desire for growth, however, if the enterprises fail to obtain legitimacy recognition and support from stakeholders, they can get little resource due to the lack of credibility and reliability and the higher competitive aggressiveness cannot be effectively transformed into a better performance. Enterprises with legitimacy will have an obvious competitive advantage compared with others since the legitimacy itself is a key resource for the growth of a new enterprise, even greater than capital, human resources, customer wishes, technology, network, etc, and it can help enterprises to obtain the other required resources as well.

Legitimizing provides an important foundation for new enterprises to get additional resources, and it also effectively affect new enterprises' resource integration and the transformation from competitive aggressiveness to performance. Accordingly, we propose the following assumption:

H2.1: For SMEs with higher legitimacy in a $\mathrm{B} 2 \mathrm{~B}$ environment, the competitive aggressiveness has a stronger influence on business performance.

\subsection{Moderating effect of reputation}

In the study about online auctions, Zhou Li'an and Zhang Weiying (2006) found that the evaluation of seller's reputation has a significant positive influence on the probability of successful auctions [27]. Based on the analysis of data from Taobao.com, Zhang Xianfeng (2009) also stressed the importance of reputation to promote selling probability and quantity [28]. These studies mostly focus on direct impacts of reputation on online-business performance, neglecting indirect effects.

Besides, some scholars focus on the moderator role of enterprise resources when they study the relationship between entrepreneurial orientation and performance. Wiklund and Shepherd (2005) investigated the moderation of financial resources and pointed out that an appropriate matching and interaction of entrepreneurial orientation, financial resources and environmental dynamics could affect the performance [29]. Chow (2006) found that human resource, especially the level of employees' education, also moderates the relationship between entrepreneurial orientation and performance [30]. Taking reputation as a strategic corporate resource like human resource and finance, this study conjectures its moderator role in the relationship between competitive aggressiveness and performance.

Meanwhile, the completion of transaction is attributed to both buyers' and sellers' intention to contact and transact. Any unilateral action can't reach a successful trade. In a B2B environment, enterprises with aggressiveness aim to provide service to customers in a timely manner, and take the initiative to establish relationship with customers. However, whether this competitive aggressiveness could improve performance or not depends on the customers' willingness and behavior to contact the sellers. During this process, enterprises with better reputation could appeal to more customers and then complete the two-way link and final deal. On the contrary, those less reputable companies, even equipped with competitive aggressiveness, find it hard to attract 
customers since they have left a bad impression, which makes them unable to encourage customers to patronize. In accordance with above discussions, this study proposes a hypothesis that:

H2.2: For SMEs with better reputation in a B2B environment, competitive aggressiveness has a stronger influence on business performance.

\section{Data and variables}

\subsection{Sample selection and data collection}

This research investigates the SMEs on B2B platforms, so we selected Alibaba.com which is the biggest B2B platform in China. The data were directly extracted from data warehouse of Alibaba.com. We randomly selected 200 member enterprises and 200 non-member enterprises for study. The results show that the corporate average registration age was 2.14 years, the average registered capital was 3.379 million Yuan and the average number of employees was 4.16.

\subsection{Competitive Aggressiveness}

Competitive aggressiveness is the response to threats. Enterprises focus on the interaction of both competitors and the market, manifested as participating in the competition decisively and effectively. Generally, on B2B platforms, companies with high competitive aggressiveness actively participate in the competition, and their business operations on the platform will be more frequent, for example, releasing the transaction information more frequently. So how often and how long companies operate on B2B platforms can reflect their competitive aggressiveness to some degree. Therefore, this study selects $\log$ in time length and log in frequency on B2B platforms to measure competitive aggressiveness. Table 1 shows the result of exploratory factor analysis of competitive aggressiveness. We can see the KMO test value is 0.5 , the Bartlett test of sphericity is 267.813 ( $\mathrm{P}$ $<0.01$ ), and ANOVA cumulative contribution rate is
$90.609 \%$. So the reliability of this result is relatively strong. Then, according to the results of factor analysis, we can extract a factor, the competitive aggressiveness.

\subsection{Performance}

Based on the operating characteristics of B2B enterprises on the internet, this research selected the amount of exposure, clicks and feedback as the indicators of corporate performance. The amount of exposure and clicks mean how many times the enterprises' products and information have been seen and clicked by buyers within specified time. The amount of feedbacks is the number of the inquiry of enterprise's products information within the specified time and it is a statistics of buyers' feedback which enterprises can get from the B2B platform. The larger the amounts of impressions, clicks and feedbacks are, the greater final trading volume is and the better performance is. Table 2 shows the results of exploratory factor analysis on performance, and the KMO test value is 0.696 , the Bartlett test of sphericity value is 707.008 $(\mathrm{P}<0.01)$, and ANOVA cumulative contribution rate is $80.87 \%$. So the reliability of this result is strong. According to the results, we can extract a factor named performance.

\subsection{Reputation}

There are mainly two approaches to evaluate the reputation of online enterprises: professionals and customers. Firstly, some professionals collect information, get directly involved in a number of online transactions and then make a judgment on e-commerce reputation based on various indicators with their expertise. Secondly, customers review, including voting, scoring and leaving messages. Neither method can avoid subjectivity: the professionals may be driven by interest to speak highly of the sellers' reputation on purpose; some sellers may attempt to 
promote their reputation grade in improper ways, such as false information published online or a vote by anonymously registered internal staff or incited consumers. Therefore, neither of them can objectively reflect the real level of corporate reputation.

TABLE I. FACTOR ANALYSIS OF COMPETITIVE AGGRESSIVENESS

\begin{tabular}{|c|c|c|c|c|c|c|}
\hline Items & Max & Min & $\begin{array}{l}\text { Mean } \\
\text { Value }\end{array}$ & $\begin{array}{l}\text { Standard } \\
\text { Deviation }\end{array}$ & $\begin{array}{l}\text { Factor } \\
\text { Loading }\end{array}$ & $\begin{array}{l}\text { Reliability } \\
\text { Coefficient }\end{array}$ \\
\hline Log in Frequency & 89 & 0 & 37.13 & 21.183 & 0.952 & 0.896 \\
\hline \multirow[t]{2}{*}{ Log in Time } & 36661.3 & 0 & 10539.146 & 8727.857 & 0.952 & \\
\hline & TABLE II & \multicolumn{5}{|c|}{ FACTOR ANALYSIS OF PERFORMANCE } \\
\hline Items & Max & Min & $\begin{array}{l}\text { Mean } \\
\text { Value }\end{array}$ & $\begin{array}{l}\text { Standard } \\
\text { Deviation }\end{array}$ & $\begin{array}{l}\text { Factor } \\
\text { Loading }\end{array}$ & $\begin{array}{l}\text { Reliability } \\
\text { Coefficient }\end{array}$ \\
\hline Impressions & 229621 & 0 & 7173.49 & 26514.982 & 0.902 & 0.881 \\
\hline Clicks & 13769 & 0 & 422.96 & 1494.717 & 0.938 & \\
\hline Feedbacks & 542 & 0 & 20.44 & 46.819 & 0.855 & \\
\hline
\end{tabular}

Resnick (2000) presented that a good reputation evaluating system must satisfy three basic conditions: to provide information for buyers to distinguish between sincere and insincere sellers; to motivate sellers to be sincere; to punish the sellers' insincerity [31]. Summarizing previous views, Dholakia (2005) also suggested that the score of reputation feedback system could play at least two roles: to help buyers recognize the difference between different sellers and make a choice; to predict, since the reputation score got from past transactions is the basis to determine whether future successful transactions can be reached or not [32].

This study selects the credibility index of online enterprises as a measure of corporate reputation. It is a third party evaluation of real corporate identity through business certificates, corporate door, office space, product display and honors, etc. Difference in scores is a clear distinction between sellers' sincerity. Buyers can see the corporate credit history through the link to understand its historical transactions. A higher score can be an incentive to sellers since it means a front rank and a greater opportunity to make a deal. Therefore, the credibility index can be taken as a standard of corporate reputation for it meets the conditions of a good reputation evaluating system.

\subsection{Legitimacy}

This research selected whether a B2B enterprise joining the integrity security system and the amount of integrity security payment as a measure of the normal legitimacy of enterprises. Integrity security services are the sellers' commitment to safeguard the interests of buyers in the transaction in the shape of security payments (or Ali Baba granting security payments) above 2,000 Yuan and signing the agreement about integrity security service. Buyers trade through Ali Pay or the security contract, so they can be compensated preferentially according to the rules when the sellers do not meet commitments. Enterprises' joining the integrity security by paying the integrity security payments reflects their efforts to get normal legitimacy by complying with the norms of e-commerce platform. By joining the integrity security, enterprises obtain the normal legitimacy.

\subsection{Control Variables}

This research selected the number of employees, the registration year and whether the enterprise is a paid member as control variables. The number of 
employees shows the enterprise's size, and it may affect the level of service and the subjective evaluation of customers to a certain extent. In the fierce competition, the enterprises with more employees generally have more strength and may have greater legitimacy and reputation [33].

TABLE III. CORRELATION COEFFICIENT MATRIX OF VARIABLES

\begin{tabular}{llllllllll}
\hline & Mean & $\begin{array}{c}\text { Standard } \\
\text { deviation }\end{array}$ & 1 & 2 & 3 & 4 & 5 & 6 & 7 \\
\hline 1 & 0.5 & 0.501 & 1 & & & & & & \\
2 & 2.34 & 1.367 & $.262^{* *}$ & 1 & & & & & \\
3 & 4.16 & 2.15 & -0.008 & 0.021 & 1 & & & & \\
4 & 0 & 1 & $.142^{*}$ & 0.062 & 0.136 & 1 & & & \\
5 & 34.7 & 48.247 & 0.049 & $.197^{* *}$ & 0.089 & $.263^{* *}$ & 1 & & \\
6 & 0.49 & 0.501 & 0.01 & 0.109 & 0.097 & $.160^{*}$ & $.305^{* *}$ & 1 & \\
7 & 0 & 1 & $.226^{* *}$ & 0.086 & 0.034 & $.395^{* *}$ & $.543^{* *}$ & $.275^{* *}$ & 1 \\
\hline
\end{tabular}

Note: 1. number of employees, 2. years of registration, 3. paid members or not, 4. competitive aggressiveness, 5 . reputation, 6. legitimacy, 7. performance; *means $\mathrm{P}<0.10$, ** means $\mathrm{P}<0.05$, the same below.

TABLE IV. MODERATED REGRESSION ANALYSIS OF LEGITIMACY AND REPUTATION ON COMPETITIVE AGGRESSIVENESS AND PERFORMANCE

\begin{tabular}{|c|c|c|c|c|c|}
\hline & \multicolumn{5}{|c|}{ Dependent variable: performance } \\
\hline & Model 1 & $\begin{array}{l}\text { Model } \\
2-1\end{array}$ & $\begin{array}{l}\text { Model } \\
2-2\end{array}$ & Model 3-1 & Model 3-2 \\
\hline Number of employees & -0.017 & -0.126 & -0.124 & 0.042 & -0.091 \\
\hline Years of registration & -0.067 & 0.035 & 0.021 & 0.033 & 0.033 \\
\hline Paid members or not & $0.165^{*}$ & -0.033 & -0.021 & 0.28 & 0.038 \\
\hline Competitive aggressiveness & & $0.424 * * *$ & $0.412 * *$ & $0.306^{* *}$ & $0.324 * * *$ \\
\hline Legitimacy & & $0.185^{*}$ & 0.168 & & \\
\hline Reputation & & & & $0.013 * * *$ & 0.003 \\
\hline Competitive aggressiveness* & & & $0155 *$ & & \\
\hline Legitimacy & & & 0.135 & & \\
\hline Competitive aggressiveness* & & & & & $0507 * * *$ \\
\hline Reputation & & & & & $0.50 / 7.6$. \\
\hline R square & 0.025 & 0.143 & 0.156 & 0.39 & 0.466 \\
\hline Adjusted R2 & 0.01 & 0.116 & 0.123 & 0.37 & 0.446 \\
\hline R2 change & & $0.118 * * *$ & $0.013 * * *$ & $0.365 * * *$ & $0.076 * * *$ \\
\hline F-value & 1.674 & $5.160 * * *$ & $4.727 * * *$ & $19.907 * * *$ & $22.587 * * *$ \\
\hline $\mathrm{N}, \mathrm{df}$ & 197,3 & 154,5 & 153,6 & 156,5 & 155,6 \\
\hline
\end{tabular}

Note: *** means $\mathrm{P}<0.01$.

The registration year may be positively related to both legitimacy and reputation. Older organizations have established roles, a history of successful accomplishments, and are more deeply embedded in networks of economic and social relationships.

Whether the enterprise is a paid member reflects 
its efforts to get more trading opportunities. Paid members can get more information and also improve its recognition of stakeholders to some extent thus influencing the performance of the enterprise.

\section{Data analysis and results}

Table 3 shows the descriptive statistics, correlation coefficient matrix and AVEs of main variables.

\subsection{Competitive aggressiveness and performance}

The regression results in Table 4 shows a significant positive relationship between competitive aggressiveness and performance $(\beta=0.424, \mathrm{P}<0.01 ; \beta$ $=0.306, \mathrm{P}<0.05$, model $2-1,3-1)$, largely supporting H1. This suggests that competitive aggressiveness of SMEs on a B2B platform can result in better performance. In the fierce competition, enterprises with strong competitive aggressiveness won't take a conservative strategy. On the contrary, they will compete effectively, launch an offensive to competitors in order to capture more market share, respond quickly to the competitors' action, identify the key resource advantages and solve problems in the operation, thus demonstrating good performance.

\subsection{Moderating effect of reputation and legitimacy}

As shown in the results, the interacted term of competitive aggressiveness and legality has a significant positive effect on corporate performance $(\beta=0.155, \mathrm{P}<0.05$, model 2-2), H2.1 supported. This indicates that legitimacy plays a moderator role in the relationship between competitive aggressiveness and performance, and for enterprises with legitimacy, and competitive aggressiveness has more impact on their performance. So, it's vital for SMEs to establish a good relationship with stakeholders and get normative legitimacy, which can help enterprises get critical resources in the transform from competitive aggressiveness to performance.
Besides, the interacted term of competitive aggressiveness and reputation also has a significant positive effect on corporate performance $(\beta=0.507, \mathrm{P}$ $<0.01$, model 3-2), H2.2 supported. This indicates that reputation plays a moderator role in the relationship between competitive aggressiveness and performance, and for enterprises with better reputation, competitive aggressiveness has more impact on performance. So, it's also vital for SMEs to establish a good image among customers.

\section{Conclusions}

In this research, we studied how legitimacy and reputation impact the relationship between the competitive aggressiveness and performance of new enterprises on B2B platforms, proposed the conceptual model of the relationship of competitive aggressiveness, legitimacy and reputation, and carried out the empirical analysis by using the data warehouse of the e-commerce platform as a data source. Two conclusions can be made from the results. First, in a B2B environment, the level of SMEs' competitive aggressiveness plays an important role in the performance and growth of the enterprise. Second, the different level of the legitimacy or reputation causes different performance even if the enterprises have the same level of competitive aggressiveness. Both legitimacy and reputation have moderating effects on the relationship between competitive aggressiveness and performance.

This research is a first step towards an analysis of the performance of SMEs on B2B platforms. Limited by time and energy, the method of data acquisition is single, so that this research selected only one dimension of legitimacy without investigating the cognitive legitimacy and regulative legitimacy, which may affect the significance of associated findings. In order to deepen the results of this research, the method of data acquisition should be diverse. Future 
research could examine whether other dimensions of legitimacy have different impacts on the relationship between competitive aggressiveness and performance, and whether other dimensions of entrepreneurial orientation have a significant positive influence on SMEs' performance on B2B platforms.

\section{References}

[1] Ren Zefeng. The research of critical successful factors in the implementation of $B 2 B$ E-Commerce for Chinese SMEs. Dissertation, Beijing Jiaotong University, 2007.

[2] Gao Xiuning. A Study on the problem of enterprise reputation.Dissertation, Huazhong University of Science \& Technology, 2004.

[3] Du Yunzhou, Ren Bing, Chen Zhongwei, Zhang Yu-li. Proactiveness, legalization and growth of SMEs-A mediation model and its implication. Management World, 2008, 12:126-138.

[4] D. Miller. The correlates of entrepreneurship in three types of firms. Management Science, 1983, 29(7):770-791.

[5] G. T. Lumpkin and Gregory G. Dess.Clarifying t he entrepreneurial orientation construct and linki ng It to performance. The Academy of Management Review, 1996, 21(1): 135-172

[6] Knight. Cross-cultural reliability and validity of a scale to measure firm entrepreneurial orientation. Journal of Business Venturing, 1997, 12(3): 213-226.

[7] Rauch, J. Wiklund, G.T. Lumpkin. Enterpreneurial orientation and business performance: Cumulative empirical evidence. Scotland: Glasgow, 2004.

[8] H. Mintzberg. Strategy making in three modes. California Management Review, 1973, 16(2): 44-53.

[9] C. MacMillan. Preemptive strategies. Journal of Business Strategy, 1983, 4(2):16-26.
[10] P. Kotler \& R. Singh. Marketing warfare in the 1980's. Journal of Business Strategy, 1981, 1(3):30-41.

[11] M. B. Lieberman. D. B. Montgomery. First-mover advantages. Strategic Management Journal, 1988, 9 (Summer):41-58.

[12] Chen Linfen. A Study on the relationship between entrepreneurial orientation and firm performance in SMEs. Dissertation, Shanghai Jiaotong University, 2007.

[13] G.T. Lumpkin, Gregory. G. Dess. Linking two dimensions of entrepreneurial orientation to firm performance: The moderating role of environment and industry life cycle. Journal of Business Venturing, 2001, 16(5):429-451.

[14] Yang Yuli. Research on entrepreneurial orientation in new enterprise. Dissertation, Jilin University, 2009.

[15] Zhang Yuli, Du Guochen. The legitimacy paradox of entrepreneurship. China Soft Science, 2007, 10:47-58.

[16] Howard E. Aldrich and C. Marlene Fiol. Fools rush in? The institutional context of industry creation. The Academy of Management Review, 1994, 19(4):645-670.

[17] Du Yunzhou, Ren Bing, Zhang Yuli. Liability of newness, legitimacy strategy and growth of new ventures. Management Review, 8:57-65.

[18] M. C. Suchman. Managing legitimacy: Strategic and institutional approaches. Academy of Management Review, 1995, 20(3):571-610.

[19] J. Pfeffer and Gerald R. Salancik. The external control of organizations:A resource dependence perspective. Harper \& Row, New York, 1978.

[20] M. A. Zimmerman and Gerald. J. Zeitz. Beyond survival: Achieving new venture growth by building legitimacy. Academy of Management Review, 2002, 27(3): 414-431.

[21] Fombrun, J. Charles. Reputation: Realizing value 
from the corporate image. Harvard Business School Press, Boston, 1995.

[22] RE. Caves \& ME. Porter. From entry barriers to mobility barriers. Quarterly Journal of Economics, 1977, 91 (2):241-261.

[23] Zhang Weiying. Property rights, government, and reputation. Sanlian, Shanghai, 2001.

[24] Li Weian, Wu Desheng, Xu Hao. Reputation mechanisms in online transaction - evidence from Taobao. Nankai Business Review, 2007, 10(5): $36-46$.

[25] Yang Juzheng, Zhang Weiying, Zhou Li'an. The complementation and substitution between reputation and surveillance - online transaction data-based empirical research. Management World, 2008, 7:18-26.

[26] Zhou Yuliang. A study on the relationship between entrepreneurial orientation and firm performance of SEMs in Zhejiang Province. Dissertation, Hangzhou Dianzi University, 2010.

[27] Zhou Li'an, Zhang Weiying, Gu Quanlin, Shen Yi. The value of reputation: taking online auction as an example. Economic Research, 2006, 12:81-91.
[28] Zhang Xianfeng. The value of reputation: the characteristic interpretation of China's electronic market based on Taobao data. Modern Economic Science, 2009, 31(3) :30-39.

[29] Johan Wiklund, Dean Shepherd. Entrepreneurial orientation and small business performance: a configurational approach. Journal of Business Venturing, 2005, 20(1): 71- 91.

[30] Chow, Irene Hau-siu. The relationship between entrepreneurial orientation and firm performance in China. SAM Advanced Management Journal, 2006, 71(3): 11-20.

[31] P. Resnick, R. Zeckhauser, E. Friedman. Reputation systems: Facilitating trust in internet interactions. Communications of the ACM, 2000, 43(12) : 45- 48.

[32] U.M Dholakia. The usefulness of bidders reputation ratings to sellers in online auctions. Journal of interactive marking, 2005, 19(1):31- 40.

[33] David L. Deephouse \& Suzanne M. Carter. An examination of differences between organizational legitimacy and organizational reputation. Journal of Management Studies, 2005, 42(2): 329-360. 